\title{
FINITE ELEEMNT FRONTAL CRASH ANALYSIS OF NEV VEHICLE'S PLATFORM WITH UPPER AND SUB FRAME BODY
}

\author{
Byeong Sam Kim*, Kyoungwoo Park, and Youn-Min Song \\ Department of Automotive Engineering, Hoseo University, Asan, Korea \\ *Correspondingauthor (kbs@hoseo.edu)
}

\begin{abstract}
In this paper, the crash analysis was performed of upper body and sub frame for NEV electric car. NEV vehicle's front platform assembly behavior when subjected to a frontal crash is described in this article. The frontal crash of the integrated car system is successfully simulated in LS-DYNA. According to the basic principle of the dynamic non-linear finite element method, the basic crash describe equation and FE discretized equation are established.
\end{abstract}

\section{Keywords: NEV Vehicle's, Frontal Crash, FEM, Sub Frame}

\section{INTRODUCTION}

The vehicle's crash analysis was used to the body structural analysis and occupant passenger behavior analysis. Analysis of the body structure has the kinetic energy of the body resulting from the absence of skeletal body collision energy can be transformed through a body that has a lot to absorb crash energy is delivered to passengers is to reduce the crash energy. In contrast, the seat of the occupant behavior analysis, seat belts, such as airbag restraint systems through the passenger has a purpose, trying to reduce the injury value.

In this paper, safety tools of passenger injury, but at less cost reduction has been much research. When the cause of vehicle crashes, the passengers inside the vehicle and the vehicle must be able to afford the same rate changes and can be free from injury. If the passengers inside the vehicle can move freely without restraint from the vehicle during a collision with the passenger's velocity relative to the speed of the car has a large value is formed inside the vehicle. However, in the passenger seat belt is to be bound by the movement that causes the deceleration of the body more time can be extended and passengers also can shrink the size of the damage that will be less.

\section{CRASH MODEL}

\subsection{Crashworthiness model}

During an accident, the capability of vehicle structure to absorb the energy is defined as crashworthiness. The vehicle must be designed such that, at higher speeds its occupants do not experience a net deceleration.

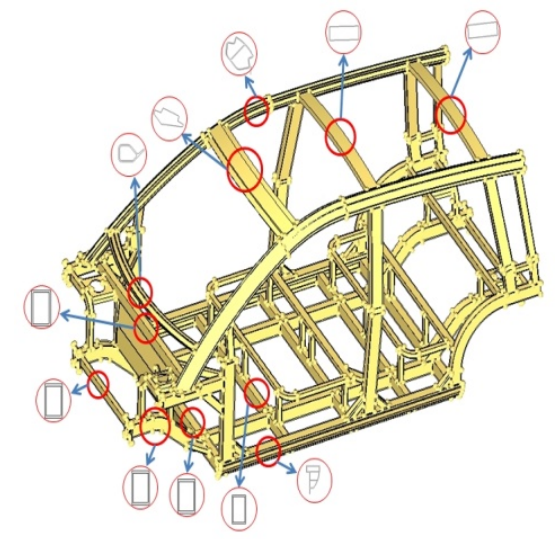

Fig. 1 EV Full Frame model in each section geometry (Front frame and sub frame)

\subsection{HEAD INJURY CRITERION (HIC)}

An Injury criterion can be defined as a biomechanical index of the passenger vehicle crashes. As a result, many countries a head injury during a car crash as a measure for estimating the degree of HIC (Head Injury Criterion), and using its result value is regulated. HIC header hit by 
injuries to the head injury, the most widely used to estimate the value equation (1) is expressed as.

$$
H I C=\left[\frac{1}{\left(t_{2}-t_{1}\right)} \int_{t_{1}}^{t_{2}} a d t\right]^{2.5}{ }^{\circ}\left(t_{2}-t_{1}\right)
$$

\subsection{FE analysis}

LS-DYNA is non-linear finite element processor which can be used to solve any kind of explicit problems. Usually in frontal impacts the vehicle undergoes heavy deformations on the front end whereas the central and the rear portions hardly undergo and deformations. Since these models are developed for frontal impacts, the front frame of the vehicle is meshed finely and the middle and the rear frame of the vehicle are coarsely meshed in Fig. 2. The type of analysis used FMVSS 208 Occupant Crash Protection on the modified regulations for non-rigid wall $30 \mathrm{mph}(48.3 \mathrm{~km}$ / h) in conflict with the speed.

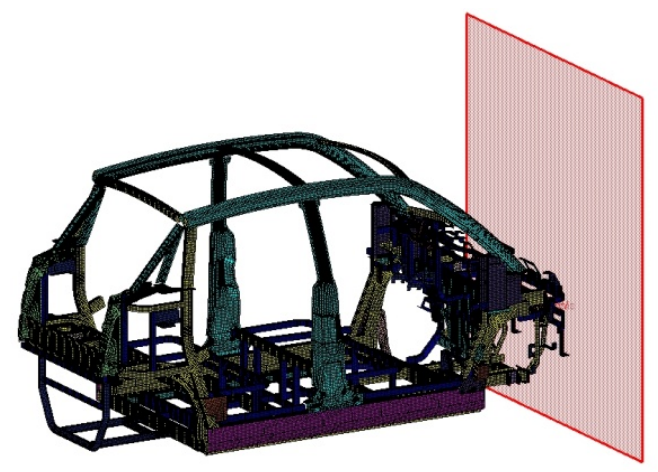

Fig. 2 FE Model for Frontal analysis using FMVSS 208

The full frontal rigid barrier analysis is carried out in LSDYNA for 120 milliseconds. The contacts are defined by geometric interface.

\section{CRASHWORTHINESS ANALYSIS}

\subsection{FE results}

The advantage of the explicit FE method is that due to the nature of the computational approach, extremely small time steps coupled with an iterative solving method. The crash analysis $120 \mathrm{~m} / \mathrm{sec}$ in the body transforms the state shown in Fig. 3, respectively with full barrier model.

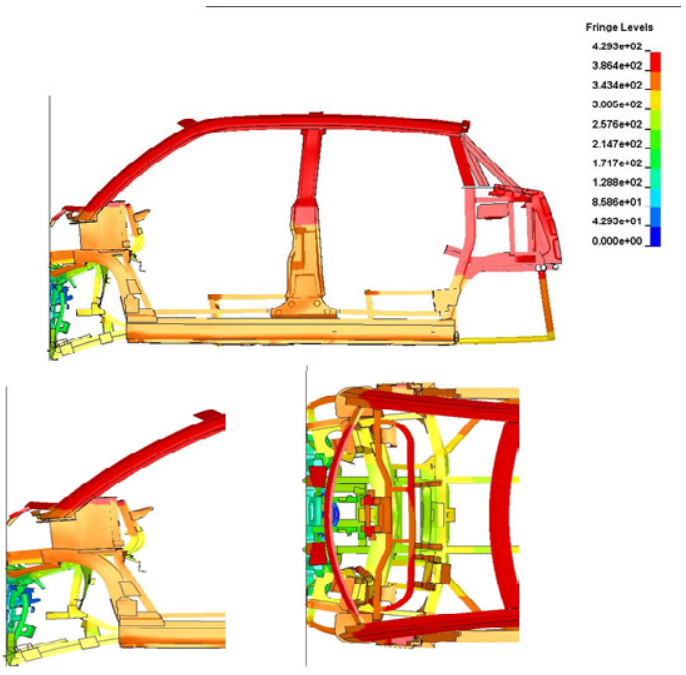

Fig. 3 Deformed Shape (Full Frontal crash with barrier, FMVSS 208, 30Mph)

The collision transformation begins in the early part of the bumper by about $8 \mathrm{~m} / \mathrm{sec}$ from the front side member and the sub-frame was the metamorphosis begins. Then about $10 \mathrm{~m} / \mathrm{sec}$ from the front frame body consists of the crash about $14 \mathrm{~m} / \mathrm{sec}$ in the sub-frame and main frame is the start of the collision. The front frame collapsed in the driver's seat the bottom of the sub-frame caused the transformation, but in the dashboard panel confirmed that the strain appeared too small. Fig. 3 shows the deformation behaviors of the front frame and the frame has been modified from conflict and at the same time. We conclude that the crash energy can be absorbed. As a Fig. 4 can be seen from front frame and the frame suspension mounts are connected to the frame associated with the departure of the wheel during a crash because it can lead to inability to drive.

Table 1 Some Material Property in Frame

\begin{tabular}{|c|c|c|c|}
\hline & $\begin{array}{c}\text { Density } \\
\left(\mathrm{kg} / \mathrm{m}^{3}\right)\end{array}$ & $\begin{array}{c}\text { Young's Modulus } \\
(\mathrm{GPa})\end{array}$ & Poisson's ratio \\
\hline $\begin{array}{c}\text { A6061- } \\
\text { T6 }\end{array}$ & 2700 & 70.5 & 0.33 \\
\hline STEEL & 7.85 & 210.0 & 0.30 \\
\hline
\end{tabular}




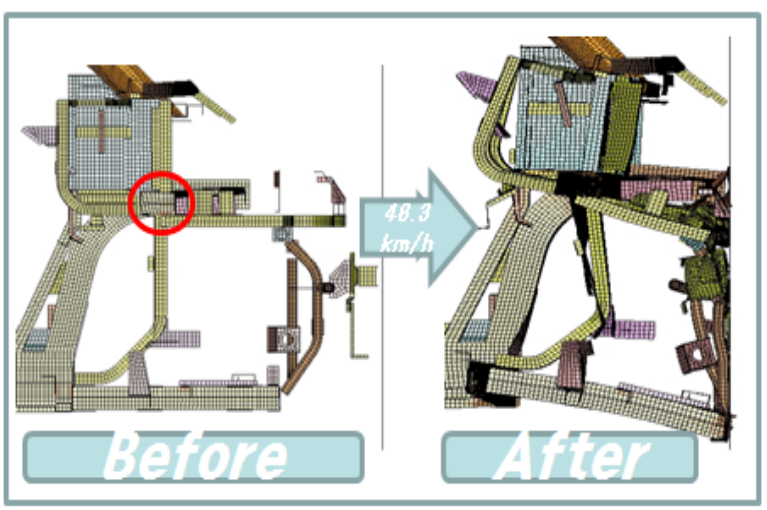

Fig. 4 Front frame deformed shape (before and after crash, FMVSS 208)

\subsection{Comparison}

In this paper, crash analysis through the EV for the upper body, and sub-frame of the mechanical characteristics compared to the simulation by EV for the upper body and the sub-frame of the collision trends and deflection for the basic data presented.

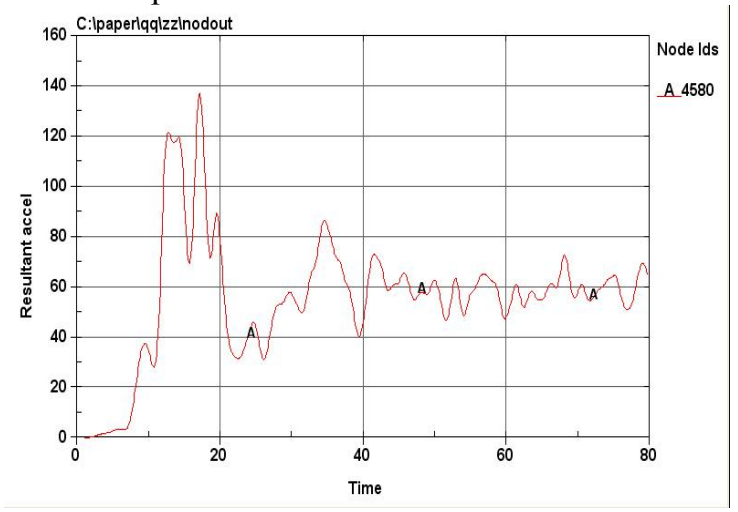

Fig. 5 Sub Frame acceleration curve

Each frame shows the results of the displacement and acceleration are the main part of the displacement and acceleration curves for the demographics. Firstly, the initial frame, the displacement value of about $425 \mathrm{~mm}$ to about $345 \mathrm{~mm}$ producing strain compared with complemented frames, but caused little variation distance between the bumper and the dash when you look at the frame model, the frame is approximately $128.2 \mathrm{~mm}$ deformed a severe strain over the frame verify that the cause may be.

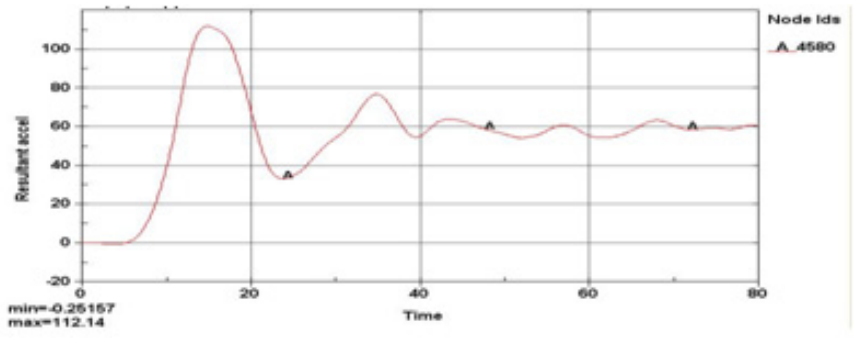

Fig. 6 Main Frame acceleration curve

This is compared to the base model for conflict acquired space frame section points through the complementary and as a result of structural changes is shown.

In addition, B-Pillar and main frame, sub-frame shows the difference in the acceleration also for the safety of passengers, especially influential in the acceleration of the B-Pillar $62.7\left(\mathrm{~mm} / \mathrm{msec}^{2}\right)$ reduced by approximately 52.68 $\left(\mathrm{mm} / \mathrm{msec}^{2}\right)$ showed more than half of the passengers going to reduce the impact can be seen as a result in Fig 5 . and Fig. 6.

Table 2 Comparison for displacement and acceleration

\begin{tabular}{|l|c|c|}
\hline & Base Frame & Modified Frame \\
\hline $\begin{array}{l}\text { Displacement / Sub } \\
\text { Frame(mm) }\end{array}$ & $345.8 / 217.6$ & $425.7 / 459.2$ \\
\hline $\begin{array}{l}\text { Main Frame } \\
\left.\text { acceleration(mm/ } \mathrm{msec}^{2}\right)\end{array}$ & 102.8 & 112.5 \\
\hline $\begin{array}{l}\text { Sub Frame } \\
\text { acceleration }\left(\mathrm{mm} / \mathrm{msec}^{2}\right)\end{array}$ & 227.5 & 138.2 \\
\hline $\begin{array}{l}\text { B-Pillar max. } \\
\text { acceleration }\left(\mathrm{mm} / \mathrm{msec}^{2}\right)\end{array}$ & 115.38 & 52.68 \\
\hline
\end{tabular}

In this study, the necessary materials for urban 4-seater electric cars are made of aluminum. The mechanical properties are shown in Table 1. The results of displacement from 12 points as the frame was chosen as mentioned above, considering the safety of the passengers were on the acceleration curve in Fig. 4. Also, when you get the acceleration curve occur because the noise is mainly used in automobile crash analysis of the SAE regulations filter $\mathrm{m} / \mathrm{sec}$ was used for a time in the $60 \mathrm{~Hz}$ to meet the curve filtering conducted noise of a reduced. 


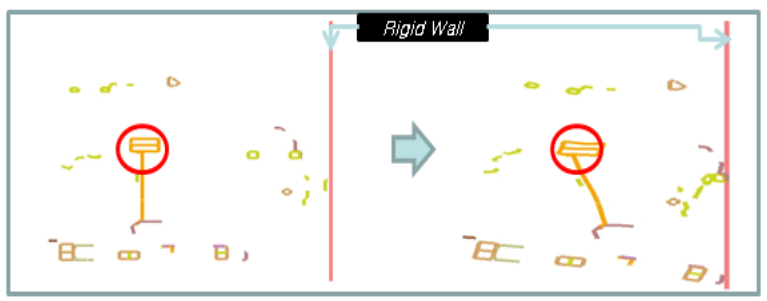

Fig. 7 Comparison movement of main frame between before and after crash with cut view section

Fig 7 shows the deformation behaviors of the front frame and the frame conflict and at the same time to absorb crash energy can see that. However, as shown in Fig 4 and Fig 7 front frame and the frame suspension mounts are connected to the frame associated with the departure of the wheel during a crash because it can lead to inability to drive could get the conclusion. The Fig 7 confirm through a cross-section of frame suspension mount the more clearly it was confirmed that the frame is pushed back. Future models will be pointed out as areas that require modification.

\section{CONCLUSION}

The purpose of this study was from the upper body for EV, and sub-frame was established to develop the analytical model simulation results were able to make predictions. The steel vehicle body frame for EV crash impact analysis performed for the Al body for the upper body of the EV, and sub-frame comparative analysis of the anterior almost no variation of power transfer due to the passenger compartment, indicating that a large strain was induced.

Thus, for EV chassis frame model of the continuous changes in design modifications were required. This model is based on the frame model, static, dynamic, impact analysis was carried out over an early model of crash energy absorption and passenger safety and has made good results in terms of content, EV for the upper body, and subframes crash analysis of the regulations (FMVSS 208) for body-frame through analysis of the conflict for an electric car will be optimized design specifications.

\section{REFERENCES}

[1] H. George Johannessen, "Historical Review of Automotive Seat Belt Restraint Systems", SAE Paper No. 870221

[2] LS-DYNA User's Manual, version 970, 2002

[3] Han. J and Yamazaki. K., "Crashworthiness optimization of S-shape square tubes". International journal of vehicle design, Vol 31, 2003.

[4] J/ Shin, S.B. Kim and al. "Consideration on the High Voltage Electric Safety Regulations of the Hydrogen Fuel Cell Vehicle", KSAE, 2010. 